\title{
Statyba
}

\section{SOIL SHEARING EQUIPMENT AND ACCURACY OF INVESTIGATION RESULTS}

\section{A. Alikonis}

To cite this article: A. Alikonis (1998) SOIL SHEARING EQUIPMENT AND ACCURACY OF INVESTIGATION RESULTS, Statyba, 4:2, 129-133, DOI: 10.1080/13921525.1998.10531392

To link to this article: https://doi.org/10.1080/13921525.1998.10531392

曲 Published online: 26 Jul 2012.

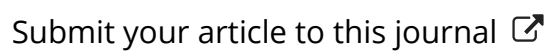

Џ Article views: 50 


\section{ТОЧНОСТЬ РЕЗУЛЬТАТОВ ИСПЫТАНИЙ ПРИБОРАМИ ДЛЯ СРЕЗА ГРУНТА}

\section{А. Аликонис}

\section{1. Введение}

Стабильность зданий и сооружений зависит от деформационных и прочностных свойств грунта основания. Эти свойства в свою очередь зависят от пористости, влажности, минерального и гранулометрического состава грунта.

Сопротивление грунта сдвигу как характеристика прочности грунта выражается величиной угла внутреннего трения и сцепления. В настоящее время деформационные и прочностные свойства грунта исследуются полевыми методами в натуральных условиях залегания грунта, однако большая часть исследований выполняется в лабораторных условиях на образцах грунта.

Параметры прочности грунта - угол внутреннего трения и сцепление - могут быть определены по результатам исследования грунта в стабилометрах и срезных приборах. В США, Великобритании, Австрии, России, Литве и других странах, кроме исследований в стабилометpax, государственными стандартами $[1,2,3,4]$ предусмотрено определение сопротивления сдвигу грунта по результатам исследования в срезных приборах. От конструкции срезных приборов во многом зависит точность полученных результатов сопротивления сдвигу сцепления и угла внутреннего трения. Для увеличения точности результатов исследования необходимо определить фактические напряжения в плоскости среза, сохранить ненарушенной структуру грунта до начала среза, избегать трения грунта о металл, т. е. о металлические части прибора во время среза, обеспечить постояннуюо скорость среза грунта при срезе автоматизированными срезными приборами.

В работах $[5,6,7$ и др.] и государственных стандартах $[1,2,3,4]$, рекомендованных для конструкций срезных приборов, не акцентированы условия, обеспечиваюшие точность результатов исследования. Наблюдение за условиями, от которых зависит точность исследований прочностных параметров, приводит $\mathrm{K}$ некоторым ошибкам и искажению значений величины сцепления и угла внутреннего трения грунта.

\section{2. Сохранение ненарушенной структуры грунта и устранение трения грунта о металл}

Известны срезные приборы для испытания грунта в лабораторных условиях на сдвиг, включающие рабочий стол, срезыватель, систему приложения вертикальной и горизонтальной нагрузок с грузами и измерительные приборы [5]. Недостатком таких приборов является то, что кольцо для грунта состоит из двух частей, что приводит $\mathrm{K}$ нарушению структуры грунта В плоскости среза при зарядке прибора и во время опыта.

Другие приборы для испытания грунта на сдвиг, включающие рабочий стол, срезыватель с подвижной и неподвижной обоймами, кольцо для грунта, механизмы для вертикальной и сдвигаюшей нагрузок, верхний и нижний штамп [6], не обеспечивают сохранности структуры грунта, особенно песчаного, в процессе погружения образца грунта в углубление нижней обоймы.

Для сохранения ненарушенной структуры грунта в процессе погружения образца грунта в углубление нижней обоймы необходимо предохранить его от свободного падения при погружении в углубление нижней обоймы $[8,9]$.

На схеме конструкции прибора для среза грунта (рис. 1) показана пружина 14, которая при перемешении грунта 5 в подвижную нижнюю обойму 2 поддерживает снизу грунт 5 через нижний штамп 9. Таким образом, она предохраняет грунт 5 от свободного падения и отрыва отдельных его частиц (особенно песчаных 
грунтов), тем самым сохраняя ненарушенной структуру грунта в плоскости среза.

После зарядки грунта нижний штамп 9 опирается на дно выемки 12 нижней подвижной обоймы 2, а пружина 14 в сжатом виде находится в углублении 13, так как во время среза поддерживает постоянной нагрузку на образец грунта.

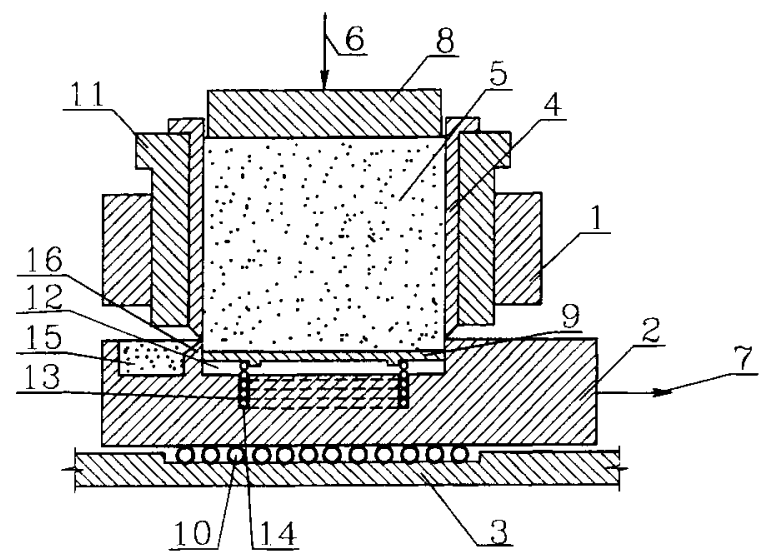

Рис. 1. Схема конструкщии прибора для среза грунта: 1 - неподвижная обойма; 2 - подвижная обойма; 3 - рабочий стол; 4 - кольцо для грунта; 5 - грунт; 6 - механизм для передачи вертикальной нагрузки; 7 - механизм для передачи сдвигаюшей нагрузки; 8 - верхний штамп; 9 - нижний ІІтамп; 10 - ролики; 11 - обойма с резьбой; 12 - выемка; 13 - углубление; 14 - пружина; 15 - выемка; 16 - перегородка

Fig 1. Soil shearing equipment: 1 - metal ring; 2 movable part of equipment; 3-lower part of equipment; 4 - ring for soil; 5 - soil: 6 - vertical load; 7 - device for shearing force; 8 - loading plate; 9 - bottom plate; 10 bell track; 11 - ring; 12 - cavity; 13 - cavity; 14 spring; 15 - cavity

При срезе грунта, как правило, передвигается нижняя часть срезного прибора. При движении нижняя часть прибора заходит в сферу верхней обоймы, поэтому уменьшается плошадь, на которой происходит трение грунта о грунт, и увеличивается площадь, на которой проявляется трение грунта о металл.

Коэффициент трения грунта о металл меняется в пределах 0,33-0,82 [10]. Для песчаных грунтов характерны большие значения коэффициентов трения, для глинистых - меньшие. Один и тот же грунт при разных значениях влажности имеет разные коэффициенты трения.

Из [10] известно, что коэффициент трения зависит, в первую очередь, от влажности и нормального давления. Он возрастает с увели- чением шероховатости металла. Коэффициент трения находится в сложной зависимости от влажности, вида грунта, удельного давления и шероховатости поверхности. Поэтому лучше избегать трения грунта о сталь при исследовании грунта в срезных приборах, нежели пытаться оценивать по каким-либо зависимостям.

При срезе грунта, особенно обладаюшего структурными связями между частицами, вначале сопротивляются связи, от которых в основном зависит сцегление. Увеличение деформации среза включает в сопротивление срезу силу трения (рис. 2, линия $\mathrm{a}-\mathrm{b}$ ).

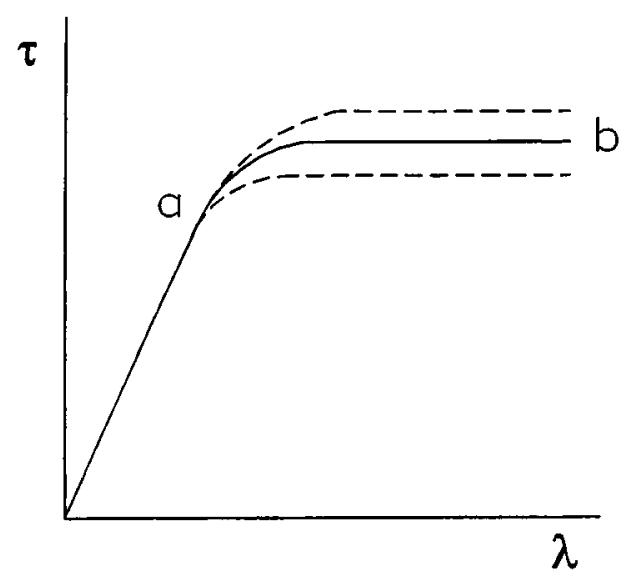

Рис. 2. Зависимость сопротивления срезу $\tau$ от деформации среза $\lambda$

Fig 2. Graph of shear resistance $\tau$ against strain $\lambda$

Если трение грунта о металл превышает трение грунта о грунт, линия $\mathrm{a}-\mathrm{b}$ (рис.2) имеет тенденцию пройти выше, а если трение грунта о металл меньше трения грунта о грунт, линия $a-b$ пройдет ниже.

Для получения точного значения коэффициента трения грунта о грунт следует избегать трения грунта о металл. Это достигается в срезном приборе (рис. 1) следуюшим образом. В подвижной нижней части прибора имеется выемка 15, которая перед срезом заполняется исследуемым грунтом. Грунт в выемке уплотняется. Выемка 15 отделена от срезаемого грунта 5 перегородкой 16 с заостренной верхней частью. Верх перегородки совпадает с верхней частью нижней подвижной обоймы 2 срезного прибора.

При срезе грунта увеличивается деформация среза, нижняя часть 2 прибора проходит под грунтом 5. Однако трение грунта о грунт не 
искажается из-за трения грунта о металІ, так как верх перегородки 16 очень тонкий и практически не оказывает влияния. График зависимости сопротивления срезу от деформации среза (рис. 2) отражает истинное трение грунта.

Таким образом, прибор, показанный на рис. 1, позволяет производить срез сыпучих и связньх грунтов при сохранении естественного сложения и структуры в процессе зарядки и подготовки прибора к испытанию, устраняет трение грунта о металл, в результате чего повышается точность и достоверность определенных сдвиговых характеристик грунта.

\section{3. Определение вертикальной нагрузки в плоскости} среза и обеспечение постоянной скорости среза в автоматизированньх срезных приборах

Вертикальная нагрузка на грунт в срезных приборах передается через верхний штамп (рис. 1). Вертикальная нагрузка из-за трения грунта о внутренние стенки кольца в неподвижжой верхней части прибора меняет свое значение в плоскости среза. Величина вертикальной нагрузки может меняться и в процессе среза [11]. При расчете параметров прочности грунта - сцепления и угла внутреннего трения принимается, что созданная сверху на образец грунта нагрузка сохраняет ту же величину и в плоскости среза. Точное значение вертикальной нагрузки в плоскости среза можно определить при помощи специальных тензометрических опор под рабочим столом прибора [12].

Вертикальная нагрузка с учетом сил трения о внутренние стенки неподвижной обоймы срезного прибора передается на подвижную обойму, т. е. на плоскость среза, а затем через ролики и рабочий стол и фиксируется тензодатчиками. Причем в процессе проведения исследований грунта тензодатчики измеряют не только истинное значение вертикальной нагрузки в плоскости среза, но и изменение этой нагрузки во время среза, что очень важно при изучении процессов, происходящих в грунте во время среза.

При срезе грунта автоматизированными приборами, когда срезывающая сила измеряется при помощи тензодатчиков, на результаты исследования влияет упругость элемента для передачи сдвигающего усилия. Элемент большой упругости не эффективен при исследовании слабых грунтов из-за малой срезываюшей силы. Элемент с тензодатчиками малой упругости для передачи связываюшей силы фиксирует любые силы, однако будет сильно деформироваться. Такой элемент в начале среза, когда грунт усиленно сопротивляется срезывающей нагрузке, будет сильно деформироваться, например, как пружина. После ослабления сопротивления срезу грунта элемент передачи силы в результате восстановительной деформации в виде освобождаюшейся пружины увеличит заданную скорость среза грунта. Таким образом, не будет обеспечена заданная постоянная скорость среза грунта.

Для обеспечения заданной постоянной скорости сдвига грунта элемент с тензодатчиками для передачи срезывающей силы подбирается в зависимости от величины максимальной силы, максимальной относительной деформации элемента, модуля упругости материала, точности измерения силы и деформации [13].

По методике [13] предварительно подбирают площадь поперечного сечения упругого элемента для передачи сдвигающего усилия на грунт, исходя из условия возможности надежной и стабильной фиксации минимального значения силы и условия сохранения заданной скорости. Элемент передачи сдвигающей силы находится между толкателкми и подвижной кареткой срезывателя и передает усилие на каретку. От действия усилия меняется длина упругого элемента, поэтому скорости толкания и подвижной каретки срезывателя не одинаковы. Чтобы обеспечить постоянную с заданной точностью скорость среза грунта, плошадь упрутого элемента подбирают, исходя из максимальной силы и допускаемой деформации упругого элемента. Упругий элемент подбирают, исходя из условия

$$
N_{\text {макс }} / \varepsilon_{\text {макс }} E<A<N_{0} / \varepsilon_{0} E
$$

или

$$
N_{\text {мaкc }} / \varepsilon_{\text {мaкc }} E \cdot A<N_{0} / \varepsilon_{0}
$$

где $N_{\text {макс }}$ - максимальная сила, передаваемая упругим элементом;

$\varepsilon_{\text {макс }}$ - максимальная относительная деформация упругого элемента, обеспечивающая требуемую точность заданной постоянной скорости сдвига грунта;

$E$ - модуль упругости материала упругого элемента, МПа; 


$$
\begin{gathered}
A-\text { поперечная площадь упругого элемента, } \\
\text { м }^{2} \\
N_{0}-\text { сила, соответствующая одному деле- }
\end{gathered}
$$
нию шкалы измерительной аппаратуры, $\mathbf{H}$;

$\varepsilon_{0}$ - минимальная относительная деформация, которую может зафиксировать измерительная аппаратура.

Упругий элемент, подобранный исходя из условия (1), обеспечит постоянную подобранную скорость среза грунта и возможность фиксации переданной силы среза. Величина сдвигағщего усилия, преобразованная с помощью тензодатчиков в электрический сигнал, поступает в графопостроитель. По ходу испытания сопротивление грунта сдвигу с какого-то момента уменышается, однако заданная скорость сдвига не изменяется и не дает обратных деформаций, искажающих заданную скорость сдвига. Увеличение длины упругого элемента влияет на результаты в пределах точности измерения.

Сохраняя заданную постоянную скорость сдвига, получаем достоверные результаты для расчета параметров прочности грунта сцепления и угла внутреннего трения.

\section{4. Заключение}

Значения параметров прочности грунта сцепления и угла внутреннего трения - зависят, кроме других факторов, от конструктивных особенностей срезного аппарата. Аппараты для испытания грунта должны обеспечивать сохранение естественной структуры грунта до начала среза, избегать трения грунта о металлические конструкщии аппарата в процессе испытания на срез, точно определять нагрузку на грунт в плоскости среза. Автоматизированные аппараты для определения сопротивления сдвигу должны обеспечивать постоянную скорость сдвига в процессе всего испытания.

Представленные в разделах 2, 3 настоящей работы способы улучшения аппаратов для исследования сопротивления сдвигу грунта могут быть применены при соверценствовании конструкции срезных приборов и увеличении точности значений параметров прочности грунта - сцепления и угла внутреннего трения

\section{Литература}

1. Standard method for direct shear test of soils under consolidated drained conditions. 1979.

2. British standard methods of test for soils for civil engineering purposes. BS 1377. 1990.

3. Erd- und Grundbau. Untersuchung von Bodenproben. Grundsatze fur die Duchfuhrung und Auswertung von Scherversuchen. ONORM B 4416.

4. Грунты. Методы лабораторного определения сопротивления срезу. ГОСТ 12248-78, с. 17.

5. С. Р. Месчян. Механические свойства грунтов и лабораторные методы их определения. М.: Недра, 1974 , c. $105-109$.

6. М. Н. Троицкая. Пособие к лабораторным работам по механике грунтов. М.: Изд-во Моск. ун-та, $1961.238 \mathrm{c}$.

7. Karl Terzaghi, Ralph B. Peck. Soil mechanics in engineering practice. Gholamreza Mesri, 1996. 128 p.

8. А. А. Аликонис. Прибор для испытания грунта на сдвиг. Описание изобретения к авторскому свидетельству № 960377. Ужтород: Филиал ППП "Патент", 1982. 2 c.

9. А. А. Аликонис. Прибор для испытания грунта на сдвиг // Прибалтийская геотехника, 7. Рига, 1991, c. $54-55$.

10. Т. А. Грязнов. Оценка показателей свойств пород полевьми методами. М.: Недра, 1984. 122 с.

11. И. Амшеюс, В. Кулешюс. Особенности определения сопротивления песчаных грунтов сдвигу аппаратом СПФ-2 // Инженерная геология, механика грунтов и фундаментостроение: Тезисы докладов межреспубликанской конференции Белорусской, Литовской, Латвийской и Эстонской ССР. Минск, 1982, c. 83-86.

12. А.-А. А. Аликонис, И. И. Амшеюс, В. Кулешюс. Прибор для испытания грунта на сдвиг. Описание изобретения к авторскому свидетельству № 1217983. Ужгород: Филиал ППП “Патент”, 1986. 2 с.

13. А.-А. А. Аликонис, И. И. Амшеюс. Способ испытания грунта на сдвиг. Описание изобретения к авторскому свидетельству № 1677578. Ужтород: Производственно-издательский комбинат "Патент", 1991. 3 с.

Поступила 26011998

\section{GRUNTO KIRPIMO PRIETAISAI IR TYRIMO REZULTATU TIKSLUMAS}

\section{A. Alikonis \\ Santrauka}

Projektuojant ivairius statinius tenka apskaičiuoti ju pagrindo stiprumą ir viso statinio stabilumą. Apskaičiavimo metodikoje naudojami pagrindo grunto stiprumo rodikliai, t. y. sankiba ir vidinès trinties kampas. Šie grunto rodikliai nustatomi eksperimentiškai. JAV, Anglijoje, Austrijoje, Lietuvoje ir kitose valstybèse, be tyrimy stabilometrais, valstybiniais standartais įteisintas grunto stiprumo parametrų nustatymas kirpimo aparatais.

Nuo grunto kirpimo aparatu konstrukcijos priklauso tyrimo rezultaty tikslumas. Norint gauti tikslius tyrimo rezultatus, reikia kuo tiksliau nustatyti itempimus grunte 
kirpimo plokštumoje, išsaugoti natūralią grunto struktūrą iki kirpimo pradžios, panaikinti trintị tarp grunto ir kirpimo prietaiso detaliu kirpimo eigoje, kerpant gruntą vienodu greičiu, užtikrinti kirpimo greičio pastovumą visoje bandymo eigoje.

Literatūroje ir valstybiniuose standartuose pateiktos kirpimo aparaty schemos rodo, kad su jais negalima ịvykdyti minetų sąlygų.

Straipsnyje pateikiami grunto kirpimo prietaisu tobulinimo būdai, pagal kuriuos galime gauti tikslius grunto stiprumo savybiu tyrimo rezultatus.

Natūralią grunto struktūrą, perstumiant gruntą i apatinę judamą prietaiso dali, gali išsaugoti speciali spyruokle, $o$ pašalinti trintị tarp grunto ir metalo - speciali išima, pripildyta tiriamo grunto (1 pav.). Tikslu grunto apkrovos kirpimo plokštumoje dydi galima nustatyti įrengus darbo stalo atramas su tenzodavikliais.

Automatizuotuose kirpimo aparatuose vienodą kirpimo greiti galima užtikrinti pagal (1) formulę parinkus kirpimo jegos perdavimo elemento skerspjūvįi ir medžiaga.

\section{SOIL SHEARING EQUIPMENT AND ACCURACY OF INVESTIGATION RESULTS}

\section{A. Alikonis}

S u m m a r y

Civil engineering works require strength and stability. Soil subbase strength parameters, ie cohesion and the angle of internal friction are used in calculations. They are experimentally determined parameters. Determination of soil strength parameters by shearbox apparatus is being legalised by standards and used along with triaxial equipment in the USA, England, Austria, Russia, Lithuania and many other countries. Accuracy of investigation results depends on the construction of soil shearing apparatus. Soil stress on shearing plane should be registrated during the test, undisturbed soil structure should be preserved before shearing is started, friction between soil and parts of shearing apparatus should be avoided and constant shear rate assured during the whole test.

Schemes of shearing apparatus presented in literature and standards show their inability of avoiding all the conditions mentioned above.

The report presents ways of improving soil shearing equipment, which leads to a more precise investigation of soil shear strength parameters.

Antanas ALIKONIS. Doctor, Associate Professor. Dept of Geotechnics, Vilnius Gediminas Technical University (VGTU). Sauletekio al. 11, 2040 Vilnius, Lithuania.

A graduate of faculty of Hydraulic Engineering of Kaunas Polytechnic Institute (civil engineer, 1958). Doctor's degree in 1968. Research visit to Moscow and Dnepropetrovsk institutes of civil engineering. Author and coauthor of 3 monographs, over 100 scientific articles; 2 patents, 5 inventions and 14 study guides. Research interests: physical and mechanical properties of soil. 